\title{
Resposta de vacas leiteiras à substituição total de milho por polpa cítrica e à suplementação com microminerais orgânicos I: Consumo e digestão
}

\author{
[Response of lactating cows to the total replacement of corn by citrus pulp and to the supplementation of organic \\ trace minerals I: Intake and digestion]
}

\section{S.C. Salvador, M.N. Pereira, J.F. Santos, L.Q. Melo, M.L. Chaves}

Universidade Federal de Lavras

Caixa Postal 3037

37200-000 - Lavras, MG

\begin{abstract}
RESUMO
Avaliou-se a resposta de vacas leiteiras à substituição total de milho maduro finamente moído por polpa cítrica peletizada. O teor dietético do milho foi $10 \%$ e o de polpa $24 \%$ nos tratamentos com milho, e o de polpa foi $33 \%$ nas dietas exclusivas com polpa. Simultaneamente, foi avaliada a substituição total de fontes inorgânicas de $\mathrm{Cu}, \mathrm{Mn}, \mathrm{Se}, \mathrm{Zn}$ e Cr por fontes orgânicas. Quatro dietas baseadas em silagem de milho foram geradas por arranjo fatorial dos dois fatores. Dezesseis vacas receberam os tratamentos em quadrado latino $4 \times 4$. O efeito da substituição de fontes inorgânicas por fontes orgânicas de microminerais não foi conclusivo. O consumo diário de matéria seca foi $19,4 \mathrm{~kg}$ na polpa e $20,5 \mathrm{~kg}$ na dieta com milho $(\mathrm{P}=0,03)$. $\mathrm{O}$ consumo de matéria orgânica digestível foi maior nas dietas com milho $(\mathrm{P}<0,01)$. Houve tendência de queda na taxa fracional de degradação ruminal in situ da MS da silagem de milho $(\mathrm{P}=0,11) \mathrm{e}$ de aumento no tamanho da fração indigestível $(\mathrm{P}=0,15)$ nas dietas com milho, sugerindo que a degradação de forragens não determinou o menor consumo nas dietas com polpa. A substituição total de milho por polpa cítrica pode reduzir o consumo e a digestibilidade.
\end{abstract}

Palavras chave: bovino, amido, pectina, rúmen, digestibilidade

\begin{abstract}
The response of lactating cows to the total replacement of finely ground mature corn by pelleted citrus pulp was evaluated. Treatments with corn contained $10 \%$ corn and $24 \%$ citrus pulp while citrus diets contained 33\% citrus pulp. The complete replacement of inorganic sources of $\mathrm{Cu}, \mathrm{Mn}, \mathrm{Se}, \mathrm{Zn}$, and $\mathrm{Cr}$ by organic sources was simultaneously evaluated. Four corn silage based diets were generated by a factorial arrangement of the two factors. Sixteen cows received the treatments in $4 \times 4$ latin squares. The effect of substituting inorganic by organic mineral sources was not conclusive. Daily dry matter intake was $19.4 \mathrm{~kg}$ for citrus diets and $20.5 \mathrm{~kg}$ with corn $(P=0.03)$. The digestible organic matter intake was increased by corn supplementation $(P<0.01)$. There was a trend for a decreased fractional rate of in situ ruminal degradation of corn silage dry matter $(P=0.11)$ and for increased size of the indigestible fraction $(P=0.15)$ in diets with corn, suggesting that degradation of forages did not determine the lower intake for citrus diets. The total substitution of corn by citrus pulp may decrease intake and digestibility.
\end{abstract}

Keywords: bovine, starch, pectin, rumen, digestibility

\section{INTRODUÇÃO}

A polpa cítrica é um subproduto fibroso da indústria de suco de laranja. A polpa é um concentrado energético rico em sacarose, pectina e fibra de boa digestibilidade (Miron et al., 2001). Entretanto, a digestão ruminal desses carboidratos difere da digestão do amido em potencial de síntese de proteína microbiana no rúmen (Dusková e Marounek, 2001; Hall e

Recebido em 6 de julho de 2007

Aceito em 24 de abril de 2008

E-mail: mpereira@ufla.br 
Herejk, 2001). A substituição total de milho por polpa cítrica, apesar de atrativa financeiramente, requer avaliação do seu efeito sobre a digestão e o consumo de vacas leiteiras.

A substituição de milho por polpa cítrica pode deprimir o consumo de vacas leiteiras de alta produção (Broderick et al., 2002; Solomon et al., 2000). Leiva et al. (2000) observaram queda no consumo médio de um grupo de 184 vacas quando uma dieta com $19,5 \%$ de milho moído e $9,6 \%$ de polpa cítrica foi substituída por outra com $9,2 \%$ de milho e $20,5 \%$ de polpa. Similarmente, a substituição de silagem de grão úmido de milho por polpa de beterraba peletizada, um alimento com características nutricionais semelhantes à polpa cítrica, também reduziu o consumo em vacas de leite (Voelker e Allen, 2003). Uma melhor compreensão do efeito da alta inclusão dietética de polpa cítrica sobre o consumo de vacas com alta produção leiteira e os possíveis mecanismos envolvidos são importantes para o uso racional deste alimento.

A função ruminal pode ser determinada pelo suprimento de macro e microminerais (Martinez e Church, 1970). Suplementos contendo microminerais complexados a moléculas orgânicas têm sido desenvolvidos industrialmente com base na teoria da maior biodisponibilidade que a de fontes inorgânicas (Spears, 1996). A indústria preconiza que minerais orgânicos teriam maior solubilidade, estrutura química estável e natureza eletricamente neutra no trato digestivo. Logo, estes não participariam de reações que poderiam transformar o íon metálico livre em complexos insolúveis indesejáveis. Foi observado que a substituição crescente de fonte inorgânica de minerais por um suplemento contendo minerais orgânicos aumentou o consumo de matéria seca e a digestibilidade em bovinos consumindo dietas de baixo valor nutritivo (Langwinski e Ospina, 2001). O efeito de curto prazo da substituição total de fontes inorgânicas por fontes orgânicas sobre a digestão e o consumo de vacas leiteiras de alta produção, consumindo dietas com teores nutricionais adequados à expressão do seu potencial produtivo, requer avaliação.

O objetivo deste trabalho foi avaliar o efeito da substituição total de milho maduro moído fino por polpa cítrica peletizada, em uma dieta- controle contendo milho e polpa como concentrados energéticos e silagem de milho como forrageira sobre a digestão e o consumo de vacas leiteiras. Concomitantemente, foi avaliada a substituição total de fontes inorgânicas de $\mathrm{Cu}$, $\mathrm{Mn}, \mathrm{Se}, \mathrm{Zn}$ e $\mathrm{Cr}$ por fontes orgânicas desses minerais.

\section{MATERIAL E MÉTODOS}

Dezesseis vacas da raça Holandesa, ordem de lactação igual a 2,1 $\pm 0,9$ partos e $168 \pm 108$ dias em lactação no início do período experimental, formaram quatro grupos de quatro animais. As vacas foram alimentadas individualmente em confinamento total. Um grupo foi formado por primíparas, outro por multíparas de maior produção de leite, outro por multíparas de menor produção de leite e um quarto grupo foi formado por uma vaca primípara e por três vacas multíparas com cânula ruminal. Dentro de cada grupo, as vacas foram aleatoriamente alocadas em uma seqüência de quatro tratamentos, em delineamento do tipo quadrado latino $4 \times 4$, realizado simultaneamente, com períodos de 21 dias e balanceados para efeito residual. Os quatro tratamentos foram formados por um arranjo fatorial 2x2: duas fontes de carboidrato do concentrado e dois tipos de mistura mineral (Tab. 1).

As duas misturas minerais foram formuladas para conter quantidades similares de micro e macrominerais. Uma mistura foi formulada apenas com fontes inorgânicas de minerais: carbonato de cálcio, fosfato bicálcico, cloreto de sódio, iodeto de cálcio, sulfato de cobalto, sulfato de cobre, fosfato de ferro, sulfato de manganês, cloreto de potássio, selenito de sódio, sulfato de zinco, cloreto de cromo e óxido de magnésio. $\mathrm{Na}$ outra, as fontes inorgânicas de selênio, zinco, cobre, manganês e cromo foram totalmente substituídas por fontes orgânicas. Na obtenção de cada fonte orgânica, fontes inorgânicas de microminerais foram industrialmente misturadas a peptídeos purificados de soja e posteriormente fermentados por culturas de leveduras ${ }^{1}$.

${ }^{1}$ Tortuga Cia Zootécnica Agrária - São Paulo, SP. 
Tabela 1. Composição das dietas oferecidas em ingredientes e das dietas consumidas em nutrientes por vacas em lactação, segundo os tratamentos

\begin{tabular}{|c|c|c|c|c|}
\hline & $\mathrm{MO}$ & MI & $\mathrm{PO}$ & PI \\
\hline \multicolumn{5}{|l|}{ Ingrediente (\% da MS) } \\
\hline Silagem de milho & 40,3 & 40,3 & 40,4 & 40,4 \\
\hline Milho maduro moído fino ${ }^{1}$ & 10,1 & 10,1 & & \\
\hline Polpa cítrica & 24,0 & 24,0 & 33,1 & 33,1 \\
\hline Farelo de soja & 11,8 & 11,8 & 12,7 & 12,7 \\
\hline Soja grão crua & 9,9 & 9,9 & 9,9 & 9,9 \\
\hline Uréia & 0,5 & 0,5 & 0,5 & 0,5 \\
\hline Bicarbonato de sódio & 1,0 & 1,0 & 1,0 & 1,0 \\
\hline Mineral orgânico $^{2}$ & 2,4 & & 2,4 & \\
\hline Mineral inorgânico $^{3}$ & & 2,4 & & 2,4 \\
\hline \multicolumn{5}{|l|}{ Nutriente } \\
\hline Proteína bruta & 17,5 & 17,8 & 17,6 & 17,5 \\
\hline FDN total & 28,5 & 28,0 & 29,5 & 30,0 \\
\hline FDN oriundo de silagem de milho & 20,6 & 21,2 & 21,3 & 20,9 \\
\hline Cinzas & 7,0 & 6,4 & 7,0 & 7,0 \\
\hline Extrato etéreo & 5,1 & 5,2 & 4,9 & 4,6 \\
\hline Carboidratos não fibrosos ${ }^{4}$ & 41,9 & 42,6 & 41,0 & 40,9 \\
\hline Matéria seca (\% da MN) & 44,6 & 44,6 & 44,6 & 44,6 \\
\hline
\end{tabular}

${ }^{\mathrm{D}}$ DKB 333B: semiduro, Dekalb (Monsanto do Brasil Ltda - São Paulo).

${ }^{2}$ Quantidade p/kg de mistura - Ca: 196g; P: 58g; Mg: 22,7g; Na: 68g; Co: 10,7mg; Cu: 742mg; Fe: 1641mg; I: 40mg; Mn: 1870mg; Se: 19mg; Zn: 2474mg, Cr: 9,7mg.

${ }^{3}$ Quantidade p/kg de mistura - Ca: 223g; P: 85g; Mg: 22,8g; Na: 44g; Co: 85mg; Cu: 740mg; Fe: 3300mg; I: 80mg; Mn: 1390mg; Se: 20mg; Zn: 2474mg; Cr: 10mg.

${ }^{4}$ Carboidratos não fibrosos $=100-$ (proteína bruta + FDN + cinzas + extrato etéreo $) . F D N=$ fibra em detergente neutro; $\mathrm{MO}=10 \%$ de milho, $24 \%$ de polpa cítrica e mineral orgânico; $\mathrm{MI}=10 \%$ de milho, $24 \%$ de polpa cítrica e mineral inorgânico; $\mathrm{PO}=33 \%$ de polpa cítrica e mineral orgânico; $\mathrm{PI}=33 \%$ de polpa cítrica e mineral inorgânico. $\mathrm{MS}=$ matéria seca; $\mathrm{MN}=$ matéria natural.

As dietas foram misturadas e oferecidas duas vezes ao dia para compor dietas completas fornecidas à vontade em quantidade suficiente para obter, no mínimo, $15 \%$ do oferecido como sobra diária. A silagem de milho, os concentrados e as sobras alimentares de cada animal foram amostrados diariamente e amostras compostas foram formadas por período experimental. O extrato etéreo foi determinado em aparelho do tipo Goldfish, conforme técnica relatada por Silva (1990), a FDN livre de cinzas o foi não seqüencialmente com a adição de amilase e sulfito de sódio (Van Soest et al., 1991) e a proteína bruta o foi pelo método de Kjeldahl (Official..., 1995). As cinzas o foram mediante incineração das amostras em mufla a $550^{\circ} \mathrm{C}$ por oito horas. As análises de minerais foram realizadas por espectrofotometria de absorção atômica com chama de acetileno ${ }^{2}$.

${ }^{2}$ Cooxupé Nutrição Animal. Cooperativa Regional de Cafeicultores - Guaxupé, MG.
O consumo de matéria seca (CMS) e as digestibilidades aparentes no trato digestivo total da matéria seca (DMS), da matéria orgânica (DMO), da FDN (DFDN) e da matéria orgânica não-FDN (DMOnFDN) foram mensurados entre os dias 16 e 19 de cada período experimental. A DMOnFDN foi utilizada como medida indireta da digestibilidade dos carboidratos não-fibrosos, já que o teor e a origem da proteína e do extrato etéreo eram similares entre as dietas. Para estimar a produção fecal, cápsulas contendo $5 \mathrm{~g}$ de óxido crômico foram fornecidas de 12 em 12 horas entre os dias oito e 19 de cada período. Amostras de fezes foram obtidas diretamente do reto entre os dias 16 e 19, de 12 em 12 horas, atrasando o início das coletas em três horas a cada dia. A concentração de cromo nas fezes foi determinada por espectrofotometria de absorção atômica (Williams et al., 1962), e calculou-se o consumo diário de matéria orgânica digestível (CMOD).

No dia 20 , amostras do fluido ruminal foram obtidas das vacas fistuladas de três em três horas, 
por um período de 24 horas. A colheita iniciouse imediatamente antes da alimentação da manhã, diretamente no saco ventral do rúmen. $\mathrm{O}$ $\mathrm{pH}$ das amostras foi determinado imediatamente após a amostragem. Registraram-se o menor valor de $\mathrm{pH}$ ruminal ao longo das 24 horas de amostragem e o tempo de sua ocorrência após a alimentação. Uma amostra foi obtida para análise de ácidos graxos voláteis (AGV) por adição de $1 \mathrm{ml}$ de ácido sulfúrico a $50 \%$ a $50 \mathrm{ml}$ de fluído ruminal e outra para a determinação de amônia, por adição de $1 \mathrm{ml}$ de ácido tricloroacético a $50 \%$. Os AGV foram analisados por cromatografia gasosa ${ }^{3}$ com coluna capilar ${ }^{4}$. A concentração total de $\mathrm{AGV}$ foi a soma do acetato, do propionato e do butirato. A análise de nitrogênio amoniacal foi realizada conforme Cotta e Russell (1982).

Entre os dias 19 e 21 de cada período, foi realizada a incubação ruminal in situ de silagem de milho seca e moída ou in natura. As amostras secas foram incubadas em sacos de náilon 100\% poliéster $(9 \times 18 \mathrm{~cm})$, contendo $5 \mathrm{~g}$ de silagem desidratada a $58^{\circ} \mathrm{C}$ por 72 horas e moída em peneira de $5 \mathrm{~mm}$, e as amostras in natura em sacos de náilon do tipo macrobag $(30 \times 11 \mathrm{~cm})$ contendo $80 \mathrm{~g}$ de silagem. As secas foram incubadas em duplicata no rúmen por $0,6,12,24$ e 72 horas, e as in natura por 0,24 e 72 horas. A matéria seca da silagem foi dividida em três frações: fração A instantaneamente degradada, fração B lentamente degradada e fração C indigestível. A fração A foi considerada como o desaparecimento por lavagem no tempo zero, a C como o resíduo da incubação por 72 horas e a B, como a matéria seca inicial subtraída de A e de C. A taxa de degradação da fração B $(k d)$ foi estimada por regressão linear, ao longo do tempo, do logarítimo natural do resíduo nos sacos incubados, como porcentagem do peso da amostra inicial, após subtração da fração $C$ desse valor. A degradação efetiva foi: $\mathrm{DEF}=\mathrm{A}+\{\mathrm{B}$ $[\mathrm{kd} /(\mathrm{kd}+\mathrm{kp})]\}$. A DEF foi calculada assumindo uma taxa fracional de passagem $(\mathrm{kp})$ de $0,05 \mathrm{~h}^{-1}$. A degradação no tempo 24 horas (DEG 24) foi o desaparecimento nos sacos incubados por 24 horas.

\footnotetext{
${ }^{3}$ Varian CP-3380 Gas Chromatograph.

${ }^{4}$ Agilent Technologies, High Performance Capillary Column 19091F-102; HP-FFAP Crosslinked FFAP.
}

As variáveis CMS, CMOD e as DMS, DMO, DMOnFDN e DFDN foram analisadas pelo procedimento GLM do pacote estatístico SAS (User's..., 1995) com o modelo: $Y_{\mathrm{ijklm}}=\mu+\mathrm{Q}_{\mathrm{i}}+$ $\mathrm{V}(\mathrm{Q})_{\mathrm{ij}}+\mathrm{P}_{\mathrm{k}}+\mathrm{C}_{1}+\mathrm{M}_{\mathrm{m}}+\mathrm{CM}_{\mathrm{lm}}+\mathrm{e}_{\mathrm{ijklm}}$, em que: $\mu$ $=$ média geral; $\mathrm{Q}_{\mathrm{i}}=$ efeito de quadrado $(\mathrm{i}=1 \mathrm{a}$ 4); $\mathrm{V}(\mathrm{Q})_{\mathrm{ij}}=$ efeito de vaca dentro de quadrado $(\mathrm{j}$ $=1$ a 16); $\mathrm{P}_{\mathrm{k}}=$ efeito de período $(\mathrm{k}=1$ a 4$) ; \mathrm{C}_{\mathrm{l}}=$ efeito de carboidrato $(1=$ milho, polpa $) ; \mathrm{M}_{\mathrm{m}}=$ efeito de mineral ( $\mathrm{m}=$ orgânico, inorgânico); $\mathrm{CM}_{\mathrm{lm}}=$ interação entre carboidrato e mineral; $\mathrm{e}_{\mathrm{ijklm}}=$ erro experimental assumido ser independente e com distribuição normal, com média zero e variância $\sigma^{2}$.

Os parâmetros cinéticos para descrever a degradação in situ da matéria seca da silagem de milho, frações A, B e C, kd, DEF e DEG 24, o valor do menor $\mathrm{pH}$ ruminal observado ao longo de 24 horas e o momento de sua ocorrência após a alimentação foram analisados com o mesmo modelo anterior, porém sem o efeito de quadrado.

O perfil de fermentação ruminal avaliado nas 24 horas, acetato, propionato, butirato, AGV total, acetato/propionato, amônia e $\mathrm{pH}$, foi analisado como medida repetida ao longo do tempo pelo procedimento MIXED do SAS (Littell et al., 1996). As estruturas de covariância testadas foram simetria composta, autorregressiva de ordem 1 e nãoestruturada. A estrutura de covariância utilizada foi aquela com o maior valor para o critério de informação de Akaike. O quadrado médio da interação período versus mineral versus concentrado versus vaca foi utilizado como medida de erro para testar o efeito de mineral, de concentrado e da interação mineral x concentrado. $\mathrm{O}$ erro residual testou o efeito de tempo após a alimentação e suas interações. $\mathrm{O}$ modelo usado foi: $\mathrm{Y}_{\mathrm{ijklm}}=\mu+\mathrm{V}_{\mathrm{i}}+\mathrm{P}_{\mathrm{j}}+\mathrm{C}_{\mathrm{k}}+\mathrm{M}_{\mathrm{l}}+\mathrm{CM}_{\mathrm{kl}}+\mathrm{T}_{\mathrm{m}}+\mathrm{CT}_{\mathrm{km}}+$ $\mathrm{MT}_{\mathrm{lm}}+\mathrm{CMT}_{\mathrm{klm}}+\mathrm{e}_{\mathrm{ijklm}}$, em que: $\mu=$ média geral; $\mathrm{V}_{\mathrm{i}}=$ efeito de vaca $(\mathrm{i}=1 \mathrm{a} 4) ; \mathrm{P}_{\mathrm{j}}=$ efeito de período $(\mathrm{j}=1$ a 4$) ; \mathrm{C}_{\mathrm{k}}=$ efeito de carboidrato $(\mathrm{k}=$ milho, polpa); $\mathrm{M}_{1}=$ efeito de mineral $(1=$ orgânico, inorgânico); $\mathrm{CM}_{\mathrm{kl}}=$ interação entre carboidrato e mineral; $\mathrm{T}_{\mathrm{m}}=$ efeito de tempo após a alimentação $(\mathrm{m}=0,3,6,9,12,15,18,21$ e 24 horas após a alimentação); $\mathrm{CT}_{\mathrm{km}}=$ interação entre carboidrato e tempo após a alimentação; $\mathrm{MT}_{\mathrm{lm}}=$ interação entre mineral e tempo após a alimentação; $\mathrm{CMT}_{\mathrm{klm}}=$ interação entre carboidrato, mineral e tempo após a alimentação; $\mathrm{e}_{\mathrm{ijk} \mathrm{km}}=$ erro experimental. 


\section{RESULTADOS E DISCUSSÃO}

As dietas em que a polpa cítrica substituiu totalmente o milho reduziram o CMS e o CMOD em cerca de $1 \mathrm{~kg}$ por dia (Tab. 2), similarmente ao observado na literatura (Solomon et al., 2000; Leiva et al., 2000; Broderick et al., 2002). A julgar pelo menor CMOD nos tratamentos formulados exclusivamente com polpa cítrica, parece que a ingestão de energia (Mertens, 1992) não foi o mecanismo regulador do consumo dessas dietas. A substituição de silagem de grão úmido de milho por teores de 6, 12 ou $24 \%$ da MS de polpa de beterraba, alimento com velocidade de hidratação alta e similar à polpa cítrica (Bhatti e Firkins, 1995), reduziu o CMS de vacas leiteiras, tendeu a aumentar a massa de digesta no rúmen de $77,7 \mathrm{~kg}$ na dieta com $0 \%$ de polpa de beterraba para $80,7 \mathrm{~kg}$ na dieta com $24 \%$ de beterraba, e aumentou o conteúdo de água na digesta ruminal (Voelker e Allen, 2003). A alta capacidade de retenção de água de alguns subprodutos fibrosos (Ramazin et al., 1994) poderia aumentar o peso e o volume de digesta úmida. Broderick et al. (2002) observaram que em um menor CMS, induzido pela substituição parcial de silagem de grão úmido de milho por polpa cítrica, não foi observada queda significativa tanto no peso quanto no volume da digesta ruminal de vacas leiteiras, sugerindo que houve maior enchimento ruminal por unidade de CMS na dieta com polpa. Hidratação das partículas alimentares e aumento do volume de digesta pode ser um mecanismo pelo qual a polpa cítrica inibiu o consumo. Diferenças no perfil de fermentação ruminal (Tab. 3) não explicaram o menor consumo nas dietas com polpa cítrica como concentrado energético único.

Tabela 2. Consumo de matéria seca e de matéria orgânica digestível e digestibilidade aparente de nutrientes no trato digestivo total de vacas em lactação, segundo os tratamentos

\begin{tabular}{lcccccccc}
\hline & MO & MI & PO & PI & EPM & P Car $^{1}$ & P Min & P Int \\
\hline Consumo, kg/d & 20,9 & 20,1 & 19,1 & 19,8 & 0,44 & 0,03 & 0,92 & 0,09 \\
CMOD, kg/d & 13,6 & 13,4 & 12,2 & 12,9 & 0,35 & $<0,01$ & 0,57 & 0,21 \\
DMS, \% & 67,9 & 68,7 & 66,2 & 67,4 & 0,66 & 0,03 & 0,12 & 0,75 \\
DMO, \% & 70,4 & 71,0 & 68,9 & 70,1 & 0,58 & 0,05 & 0,12 & 0,64 \\
DFDN, \% & 42,8 & 38,3 & 37,1 & 41,3 & 1,75 & 0,47 & 0,92 & 0,02 \\
DMOnFDN, \% & 82,6 & 84,6 & 83,2 & 83,5 & 0,63 & 0,70 & 0,07 & 0,14 \\
\hline
\end{tabular}

$\mathrm{MO}=10 \%$ de milho, $24 \%$ de polpa cítrica e mineral orgânico; $\mathrm{MI}=10 \%$ de milho, $24 \%$ de polpa cítrica e mineral inorgânico; $\mathrm{PO}=33 \%$ de polpa cítrica e mineral orgânico; $\mathrm{PI}=33 \%$ de polpa cítrica e mineral inorgânico. $\mathrm{EPM}=$ erro-padrão da média. $\mathrm{CMOD}=$ consumo de matéria orgânica digestível; $\mathrm{DMS}=$ digestibilidade da matéria seca; $\mathrm{DMO}=$ digestibilidade da matéria orgânica; $\mathrm{DFDN}=$ digestibilidade da fibra em detergente neutro; DMOnFDN= digestibilidade da matéria orgânica não-FDN.

${ }^{1}$ Probabilidade para os efeitos de: Car $=$ carboidrato, Min= mineral e Int= interação Car x Min. Digestibilidade: \% do consumido.

Tabela 3. Perfil de fermentação ruminal de vacas em lactação, segundo os tratamentos

\begin{tabular}{lcccccccc} 
& MO & MI & PO & PI & EPM & $P$ Car & $P$ Min & $P$ Int \\
\hline Acetato, mM & 41,1 & 43,4 & 47,3 & 48,4 & 3,29 & 0,18 & 0,61 & 0,85 \\
Propionato, mM & 15,7 & 16,9 & 17,9 & 17,9 & 1,33 & 0,34 & 0,71 & 0,61 \\
Butirato, mM & 7,0 & 7,6 & 8,2 & 8,2 & 0,56 & 0,21 & 0,62 & 0,61 \\
AGV total, mM & 63,7 & 67,9 & 73,4 & 74,3 & 5,09 & 0,21 & 0,63 & 0,75 \\
A/P & 2,71 & 2,65 & 2,74 & 2,80 & 0,055 & 0,23 & 0,97 & 0,36 \\
\hline Amônia, mg/dl & 21,4 & 21,9 & 19,7 & 20,6 & 1,27 & 0,33 & 0,58 & 0,86 \\
pH & 6,73 & 6,70 & 6,68 & 6,78 & 0,047 & 0,76 & 0,48 & 0,22 \\
pH mínimo & 6,30 & 6,32 & 6,21 & 6,34 & 0,058 & 0,61 & 0,26 & 0,37 \\
Tempo pH $^{2}$ & 12,2 & 14,1 & 14,2 & 11,2 & 2,18 & 0,88 & 0,80 & 0,31 \\
\hline
\end{tabular}

$\mathrm{MO}=10 \%$ de milho, $24 \%$ de polpa cítrica e mineral orgânico; $\mathrm{MI}=10 \%$ de milho, $24 \%$ de polpa cítrica e mineral inorgânico; $\mathrm{PO}=33 \%$ de polpa cítrica e mineral orgânico; $\mathrm{PI}=33 \%$ de polpa cítrica e mineral inorgânico. $\mathrm{EPM}=$ erro-padrão da média.

${ }^{1}$ Probabilidade para os efeitos de Car= carboidrato; Min= mineral e Int= interação Car x Min.

$\mathrm{A} / \mathrm{P}=$ relação entre acetato e propionato. $\mathrm{P}<0,001$ para o efeito de tempo de amostragem. $\mathrm{P}<0,01$ para a interação tempo, Car e Min.

${ }^{2}$ Tempo após alimentação no qual foi observado o menor valor de $\mathrm{pH}$ ruminal (em horas). 
A variação no $\mathrm{pH}$ ruminal (Fig. 1) parece indicar que esse mecanismo não foi um determinante importante do menor CMS quando a polpa cítrica foi fornecida como único concentrado energético neste experimento. $\mathrm{O}$ valor do $\mathrm{pH}$ médio e a média do mínimo valor de $\mathrm{pH}$ observados ao longo do dia não variaram entre tratamentos (Tab. 3). O baixo $\mathrm{pH}$ ruminal pode aumentar a velocidade de absorção dos AGV pela parede do rúmen (Dijkstra et al., 1993), potencialmente capaz de aumentar o estímulo químico aos receptores vagais inibidores da motilidade ruminal (Crichlow e Leek, 1986; Cottrell e Gregory, 1991). Rosendo et al. (1999) observaram in vitro que a fermentação com pectina tendeu a atingir um valor mínimo de $\mathrm{pH}$ mais rapidamente que a fermentação com amido. Tanto sacarose quanto pectina foram capazes de induzir o crescimento microbiano in vitro mais rapidamente que o amido (Hall e Herejk, 2001). Leiva et al. (2000) observaram queda mais rápida no $\mathrm{pH}$ ruminal de vacas leiteiras quando a polpa cítrica substituiu o milho, semelhante ao observado por Costa (2002), quando $0,8 \%$ do peso vivo de polpa cítrica ou milho maduro finamente moído foi introduzido em dose única pela cânula ruminal de vacas não lactantes.

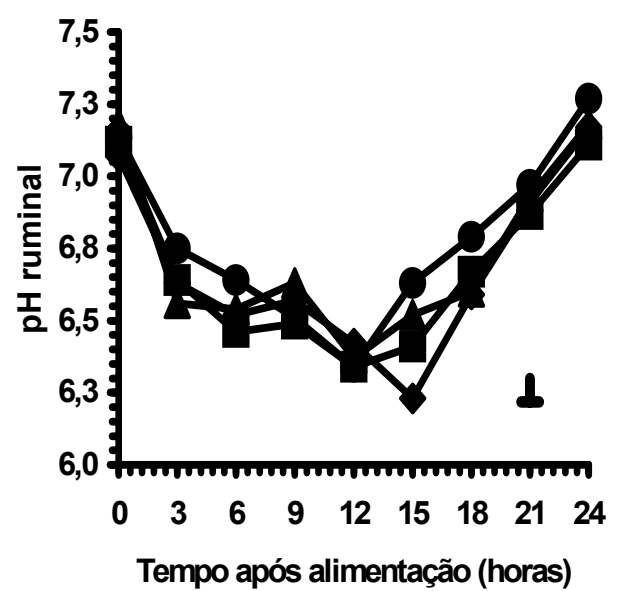

Figura 1. pH ruminal de acordo com os tratamentos: $\boldsymbol{\Delta}=10 \%$ de milho, $24 \%$ de polpa cítrica e mineral orgânico; $\mathbf{\square}=10 \%$ de milho, $24 \%$ de polpa cítrica e mineral inorgânico; $\diamond=$ $33 \%$ de polpa cítrica e mineral orgânico; $\mathbf{O}=33 \%$ de polpa cítrica e mineral inorgânico). $\mathrm{P}<0,01$ para o efeito de tempo e $\mathrm{P}=0,34$ para o efeito da interação tempo $\mathrm{x}$ carboidrato $\mathrm{x}$ mineral. A barra representa o erro-padrão da média.

Nas dietas formuladas exclusivamente com polpa cítrica ocorreu maior concentração ruminal de AGV nos tempos de amostragem imediatamente após alimentação da manhã (tempos 3 e 6) e a da tarde (tempos 12 e 15) (Fig. 2), tempos nos quais também foram observadas baixas relações A/P (Fig. 3). A concentração ruminal de amônia após a alimentação foi mais alta nos tratamentos com milho (Fig. 4), sugerindo que o amido do milho, de alta vitreosidade em estádio maduro de maturação, pode ter induzido menor taxa de crescimento microbiano logo após a alimentação que os carboidratos da polpa cítrica, coerente com os resultados in vitro de Hall e Herejk (2001). Parece que nessas dietas as concentrações de $\mathrm{AGV}$ e de amônia no rúmen foram melhores indicadores da diferença no metabolismo ruminal dos substratos que o $\mathrm{pH}$ do fluido.

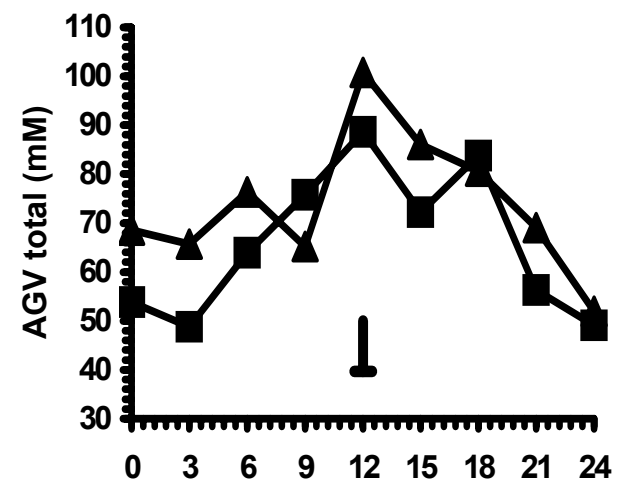

Tempo após alimentação (horas)

Figura 2. Ácidos graxos voláteis $(\mathrm{AGV})$ de acordo com os tratamentos: $\mathbf{\square}=10 \%$ de milho e $24 \%$ de polpa cítrica e $\boldsymbol{\Delta}=$ $33 \%$ de polpa cítrica. $\mathrm{P}<0,01$ para o efeito de tempo e $\mathrm{P}=0,84$ para o efeito da interação tempo $\mathrm{x}$ carboidrato. A barra representa o erro-padrão da média.

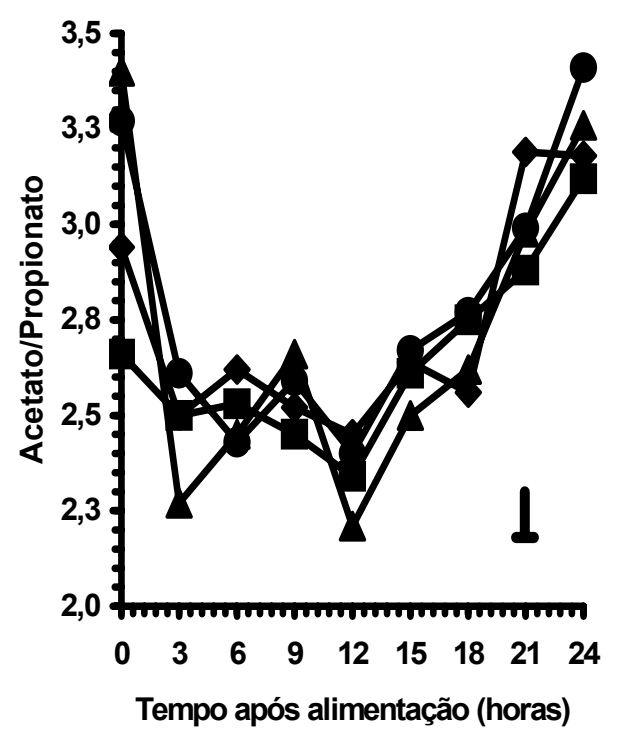

Figura 3. Relação acetato/propionato de acordo com os tratamentos: $\boldsymbol{\Delta}=10 \%$ de milho, $24 \%$ de polpa cítrica e mineral orgânico; $\square=10 \%$ de milho, $24 \%$ de polpa cítrica e mineral inorgânico; $\quad=33 \%$ de polpa cítrica e mineral orgânico; $=33 \%$ de polpa cítrica e mineral inorgânico. $\mathrm{P}<0,01$ para o efeito de tempo e $\mathrm{P}<0,01$ para o efeito da interação tempo x mineral $\mathrm{x}$ carboidrato. A barra representa $\mathrm{o}$ erro-padrão da média. 


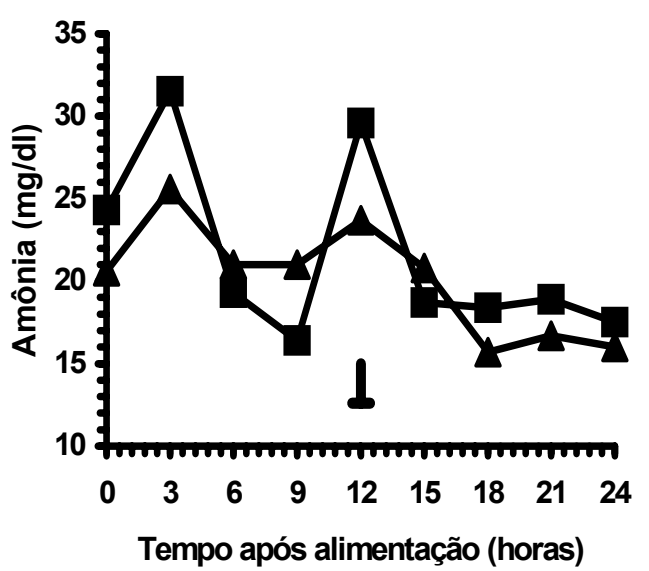

Figura 4. Amônia ruminal de acordo com os tratamentos: $10 \%$ de milho e $24 \%$ de polpa cítrica e $\boldsymbol{\Delta}=33 \%$ de polpa cítrica. $\mathrm{P}<0,01$ para o efeito de tempo e $\mathrm{P}=0,53$ para o efeito da interação tempo x carboidrato. A barra representa o erropadrão da média.
A fração A da silagem de milho foi $148 \%$ maior quando estimada com amostras desidratadas e moídas, enquanto a fração $\mathrm{C}$, menor nas amostras secas e moídas que nas amostras incubadas in natura, foi menos afetada pela técnica de mensuração da degradabilidade in situ (Tab. 4). Nas dietas com milho, o $\mathrm{kd}$, mensurado em amostras frescas, e o tamanho da fração $\mathrm{C}$, mensurado em amostras secas e moídas, tenderam a cair e a aumentar, respectivamente, indicando que houve queda na degradabilidade ruminal da matéria seca da forragem nessa dieta. A similaridade no $\mathrm{pH}$ ruminal entre tratamentos (Tab. 3, Fig. 1) sugere que a presença de amido no rúmen pode ter induzido efeito negativo sobre a degradabilidade ruminal da forragem (Grant e Mertens, 1992). A degradação das forragens no rúmen não explica o menor CMS nas dietas com polpa, já que nas dietas com milho, aparentemente depressoras da degradabilidade ruminal da forragens, foi observado maior CMS.

Tabela 4. Degradabilidade in situ da matéria seca da silagem de milho, incubada após desidratação e moagem ou incubada in natura, de vacas em lactação, segundo os tratamentos

\begin{tabular}{|c|c|c|c|c|c|c|c|c|}
\hline & $\mathrm{MO}$ & $\mathrm{MI}$ & $\mathrm{PO}$ & PI & EPM & $P$ Car $^{1}$ & $P$ Min & $P$ Int \\
\hline \multicolumn{9}{|c|}{ Desidratada e moída (\% da MS) } \\
\hline Fração A & 37,7 & 37,7 & 37,7 & 37,7 & & & & \\
\hline Fração B & 30,2 & 29,5 & 33,3 & 34,7 & 2,3 & 0,15 & 0,89 & 0,64 \\
\hline Fração C & 32,0 & 32,8 & 29,0 & 27,5 & 2,3 & 0,15 & 0,89 & 0,64 \\
\hline DEG 24 & 52,6 & 55,6 & 54,1 & 53,8 & 2,6 & 0,96 & 0,60 & 0,55 \\
\hline DEF & 48,3 & 51,2 & 50,7 & 51,2 & 1,8 & 0,51 & 0,42 & 0,60 \\
\hline $\mathrm{kd} \mathrm{de} \mathrm{B}, \mathrm{h}^{-1}$ & $-0,029$ & $-0,039$ & $-0,032$ & $-0,033$ & 0,004 & 0,71 & 0,25 & 0,27 \\
\hline \multicolumn{9}{|c|}{ In natura $(\% \mathrm{MS})$} \\
\hline Fração A & 15,2 & 15,2 & 15,2 & 15,2 & & & & \\
\hline Fração B & 47,3 & 50,6 & 47,2 & 48,6 & 1,5 & 0,56 & 0,19 & 0,58 \\
\hline Fração C & 37,5 & 34,2 & 37,6 & 36,2 & 1,5 & 0,56 & 0,19 & 0,57 \\
\hline DEG 24 & 45,6 & 46,0 & 46,7 & 46,9 & 0,9 & 0,38 & 0,75 & 0,89 \\
\hline DEF & 37,0 & 37,4 & 37,8 & 38,0 & 0,7 & 0,38 & 0,69 & 0,90 \\
\hline $\mathrm{kd} \mathrm{de} \mathrm{B}, \mathrm{h}^{-1}$ & $-0,043$ & $-0,038$ & $-0,047$ & $-0,046$ & 0,002 & 0,11 & 0,30 & 0,48 \\
\hline
\end{tabular}

$\mathrm{MO}=10 \%$ de milho, $24 \%$ de polpa cítrica e mineral orgânico; $\mathrm{MI}=10 \%$ de milho, $24 \%$ de polpa cítrica e mineral inorgânico; $\mathrm{PO}=33 \%$ de polpa cítrica e mineral orgânico; $\mathrm{PI}=33 \%$ de polpa cítrica e mineral inorgânico. EPM= erropadrão da média. Fração $\mathrm{A}=$ instantaneamente degradada no rúmen. Fração $\mathrm{B}=$ lentamente degradada no rúmen; fração $\mathrm{C}=$ indigestível. DEG 24= desaparecimento de matéria seca do saco incubado por 24 horas; $\mathrm{DEF}=$ degradação efetiva assumindo $\mathrm{kp}$ de $-0,05 \mathrm{~h}^{-1}$. kd de $\mathrm{B}=$ taxa fracional de degradação da fração $\mathrm{B}$.

${ }^{1}$ Probabilidade para os efeitos de Car= carboidrato; Min= mineral e Int= interação Car x Min.

A composição analisada das fórmulas orgânica e inorgânica não foi idêntica (Tab. 1) e para todos os macro e microminerais a composição da dieta oferecida excedeu as exigências nutricionais mínimas preconizadas pelo modelo nutricional do Nutrient... (2001). Os teores de minerais na dieta foram sempre iguais ou superiores a: $\mathrm{Ca}$, $1,1 \% ; \mathrm{P}, 0,42 \% ; \mathrm{Mg}, 0,25 \% ; \mathrm{K}, 1,03 \% ; \mathrm{Na}$, 0,41\%; Co, 0,37ppm; Cu, 29ppm; Mn, 54,8ppm;
Zn, 85,6ppm; Se, 0,5ppm; I, $1 \mathrm{ppm}$ e Cr, 0,24ppm. Para os macrominerais $\mathrm{Ca}$ e $\mathrm{P}$, houve efeito do suplemento mineral utilizado sobre o teor dos nutrientes na dieta. A concentração dietética de Ca por tratamento foi: $1,1 \%$ no $\mathrm{MO}$, $1,2 \%$ no MI, $1,3 \%$ no PO e $1,3 \%$ no PI, todas capazes de suprir praticamente o dobro da exigência nutricional de $\mathrm{Ca}$. A concentração de $\mathrm{P}$ foi: $0,43 \%$ no $\mathrm{MO}, 0,50 \%$ no MI, $0,42 \%$ no PO e 
0,49\% no PI, também em excesso à exigência nutricional em todas as dietas. Carbonato de cálcio e fosfato bicálcico foram utilizadas como fontes desses minerais, ambas consideradas fontes com alto coeficiente de absorção (Nutrient..., 2001). Dentre os microminerais, houve variação entre dietas apenas no teor de Co, Mn e I. A concentração de Co foi: $0,37 \mathrm{ppm}$ no $\mathrm{MO}, 2,23 \mathrm{ppm}$ no $\mathrm{MI}, 0,38 \mathrm{ppm}$ no $\mathrm{PO}$ e $2,25 \mathrm{ppm}$ no PI; a de $\mathrm{Mn}$ : foi: $68,9 \mathrm{ppm}$ no $\mathrm{MO}, 56,8 \mathrm{ppm}$ no MI, 66,9ppm no PO e 54,8ppm no PI; e a de I: $1 \mathrm{ppm}$ no $\mathrm{MO}, 2 \mathrm{ppm}$ no $\mathrm{MI}, 1 \mathrm{ppm}$ no $\mathrm{PO}$ e $2 \mathrm{ppm}$ no PI. Os microminerais em forma orgânica substituíram sulfatos de $\mathrm{Cu}, \mathrm{Mn}$ e $\mathrm{Zn}$ e selenito de sódio, todas consideradas fontes inorgânicas com alto coeficiente de absorção.

Não foi detectado efeito do tipo da mistura mineral sobre as variáveis descrevendo a função ruminal (Tab. 3 e 4). Minerais orgânicos induziram queda na DFDN na dieta com polpa e aumento na dieta com milho (Tab. 2). Seguindo essa tendência, a mistura com minerais orgânicos aumentou o CMS na dieta com milho e reduziu o CMS na dieta exclusivamente de polpa cítrica $(\mathrm{P}=0,09$ para a interação mineral $\mathrm{x}$ carboidrato $)$. $\mathrm{O}$ mecanismo desse fenômeno não é claro. A simples variação nos teores dietéticos de $\mathrm{P}, \mathrm{Ca}$, Co, Mn e I, quando da substituição da mistura inorgânica pela mistura contendo orgânicos, não explica as interações carboidrato versus mineral, já que a superioridade ou inferioridade do suplemento orgânico em relação ao inorgânico ocorreu tanto na dieta com milho quanto na dieta apenas com polpa cítrica.

A comparação entre minerais orgânicos e inorgânicos neste trabalho deve ser interpretada como uma resposta de curto prazo em dietas em que a concentração de todos os minerais foi acima da exigência nutricional, na qual as fontes orgânicas substituíram completamente as boas fontes inorgânicas. Inferências são provavelmente incorretas para prever a resposta animal a longo prazo, para inferir quanto à substituição de fontes inorgânicas de menor biodisponibilidade por esse tipo de fonte orgânica, ou para prever a resposta em dietas em que os teores dietéticos de minerais se aproximam dos limites mínimos de inclusão dietética relativamente à exigência nutricional do animal. Também é importante enfatizar que esses animais não estavam sujeitos a estresse acentuado, pois eram vacas de alta produção, que não se encontravam em período peri-parto $\mathrm{e}$ foram mantidas em boa condição nutricional. Em bovinos, respostas positivas à suplementação com fontes orgânicas de microminerais foram observadas em situações de estresse, normalmente associadas a desafios sanitários (Chirase et al., 1991) ou à condição fisiológica própria da vaca leiteira no peri-parto (Hayirli et al., 2001), ou quando fontes orgânicas foram comparadas a fontes inorgânicas de baixa biodisponibilidade (Pereira, 2002).

\section{CONCLUSÕES}

Em dietas baseadas em silagem de milho, a substituição total de milho maduro moído fino por polpa cítrica peletizada reduziu os consumos de matéria seca e de energia.

\section{REFERÊNCIAS BIBLIOGRÁFICAS}

BHATTI, S.A.; FIRKINS, J.L. Kinetics of hydration and functional specific gravity of fibrous feed byproducts. J. Anim. Sci., v.73, p.1449-1458, 1995.

BRODERICK, G.A.; MERTENS, D.R.; SIMONS, R. Efficacy of carbohydrate sources for milk production by cows fed diets based on alfalfa silage. J. Dairy Sci., v.85, p.1767-1776, 2002.

CHIRASE, N.K.; HUTCHESON, D.P.; THOMPSON, G.B. Feed intake, rectal temperature, and serum mineral concentrations of feedlot cattle fed zinc oxide or zinc methionine and challenged with infectious bovine rhinotracheitis virus. J. Anim. Sci., v.69, p.4137-4145, 1991.

CONRAD, H.R.; PRATT, A.D.; HIBBS, J.W. Regulation of feed intake in dairy cows. I. Change in importance of physical and physiological factors with increasing digestibility. J. Dairy Sci., v.47, p.54-62, 1964.

COSTA, H.N. Efeito do ambiente ruminal sobre a degradabilidade in situ da cana-de-açucar. 2002. 51f. Dissertação (Mestrado) - Universidade Federal de Lavras, Lavras, MG.

COTTA, M.A.; RUSSELL, J.B. Effect of peptides and amino acids on efficiency of rumen bacterial protein synthesis in continuous culture. J. Dairy Sci., v.65, p.226-234, 1982.

COTTRELL, D.F.; GREGORY, P.C. Regulation of gut motility by luminal stimuli in the ruminant. In: SYMPOSIUM RUMINANT PHYSIOLOGY: PHYSIOLOGICAL ASPECTS OF DIGESTION 
AND METABOLISM IN RUMINANTS, 7., 1991, San Diego. Proceedings...San Diego, CA, 1991. p.3.

CRICHLOW, E.C.; LEEK, B.F. Forestomach epithelial receptor activation by rumen fluids from sheep given intraruminal infusions of volatile fatty acids. Am. J. Vet. Res., v.47, p.1015-1018, 1986.

DIJKSTRA, J.; BOER, H.; VAN BRUCHEM, J. et al. Absorption of volatile fatty acids from the rumen of lactating dairy cows as influenced by volatile fatty acid concentration, $\mathrm{pH}$ and rumen liquid volume. $\mathrm{Br}$. J. Nutr., v.69, p.385-396, 1993.

DUSKOVA, D.; MAROUNEK, M. Fermentation of pectin and glucose, and activity of pectin-degrading enzymes in the rumen bacterium Lachnospira multiparus. Letters App. Microbiol., v.33, p.159-163, 2001.

GRANT, R.J.; MERTENS, D.R. Influence of buffer $\mathrm{pH}$ and raw corn starch addition on in vitro fiber digestion kinetics. J. Dairy Sci., v.75, p.2762-2768, 1992.

HALL, M.B.; HEREJK, C. Differences in yields of microbial crude protein from in vitro fermentation of carbohydrates. J. Dairy Sci., v.84, p.2486-24893, 2001.

HAYIRLI, A.; BREMMER, D.R.; BERTICS, S.J. et al. Effect of chromium supplementation on production and metabolic parameters in periparturient dairy cows. J. Dairy Sci., v.84, p.1218-1230, 2001.

LANGWINSKI, D.; OSPINA, H. A nutrição de ruminantes $e$ os complexos orgânicos de minerais. Porto Alegre: Tortuga Companhia Zootécnica Agrária, 2001. $52 \mathrm{p}$.

LEIVA, E.; HALL, M.B.; VAN HORN, H.H. Performance of dairy cattle fed citrus pulp or corn products as sources of neutral detergent-soluble carbohydrates. J. Dairy Sci., v.83, p.2866-2875, 2000.

LITTELL, R.C.; MILLIKEN, G.A.; STROUP, W.W. et al. $S A S^{\circledast}$ system for mixed models. Cary: SAS Institute Inc, 1996. 633p.

MARTINEZ, A.; CHURCH, D.C. Effect of various mineral elements on in vitro rumen cellulose digestion. J. Dairy Sci., v.31, p.982-990, 1970.

MERTENS, D.R. Nonstructural and structural carbohydrates. In: Van HORN, H.H.; WILCOX, C.J. Large dairy herd management. Champaign: American Dairy Science Association, 1992. p.219-235.

MIRON, J.; YOSEF, E.; BEN-GHEDALIA, D. Composition and in vitro digestibility of monosaccharide constituents of selected byproduct feeds. J. Agric. Food Chem., v.49, p.2322-2326, 2001.
NUTRIENT requirements of dairy cattle. 7.ed. Washington: National Academy of Sciences, 2001. $381 \mathrm{p}$.

OFFICIAL methodos of analysis of AOAC International. 16.ed. Arlington: AOAC International, 1995. v.1.

PEREIRA, M.N. Minerais orgânicos em dietas para ruminantes. In: SIMPÓSIO SOBRE INGREDIENTES NA ALIMENTAÇÃO ANIMAL, 2., 2002, Uberlândia. Anais... Uberlândia: Colégio Brasileiro de Nutrição Animal, 2002. p.193-206.

RAMANZIN, M.; BAILONI, L.; BITTANTE, G. Solubility, water-holding capacity and specific gravity of different concentrates. J. Dairy Sci., v.77, p.774$781,1994$.

ROSENDO, O.; MAY, M.B.; STAPLES, C.R. et al. Effects of polysaccharides on fiber digestion kinectics and microbial protein production in vitro. J. Dairy Sci., v.82, suppl. 1, p.89, 1999.

SILVA, D. J. Análise de alimentos (métodos químicos e biológicos). Viçosa: UFV, 1990. 166p.

SOLOMON, R.; CHASE, L.E.; BEN-GHEDALIA, D. et al. The effect of nonstructural carbohydrate and addition of full fat extruded soybeans on the concentration of conjugated linoleic acid in the milk fat of dairy cows. J. Dairy Sci., v.83, p.1322-1329, 2000.

SPEARS, J.W. Organic trace minerals in ruminant nutrition. Anim. Feed Sci. Techn., v.58, p.151-163, 1996.

USER'S guide: statistics. 6.03 ed. Cary: SAS Institute, 1995. $1028 \mathrm{p}$.

VAN SOEST, P.J. Nutritional ecology of ruminant. 2.ed. Ithaca: Cornell University, 1994. 476 p.

VAN SOEST, P.J.; ROBERTSON, J.B.; LEWIS, B.A. Methods for dietary fiber, neutral detergent fiber, and nonstarch polysaccharides in relation to animal nutrition. J. Dairy Sci., v.74, p.3583-3597, 1991.

VOELKER, J.A.; ALLEN, M.S. Pelleted beet pulp substituted for high-moisture corn: 1 . Effects on feed intake, chewing behavior, and milk production of lactating dairy cows. J. Dairy Sci., v.86, p.3542-3552, 2003.

WEIDNER, S.J.; GRANT, R.J. Altered ruminal mat consistency by high percentages of soybean hulls fed to lactating dairy cows. J. Dairy Sci., v.77, p.522-532, 1994.

WILLIAMS, C.H.; DAVID, D.J.; IISMAA, O. The determination of chromic oxide in faeces samples by atomic absorption spectrophotometry. J. Agric. Sci., v.59, p.381-385, 1962. 